\title{
EsTIMACIÓN DE LAS CATEGORÍAS MARXIANAS MEDIANTE TABLAS DE INSUMO-PRODUCTO. UN ANÁLISIS COMPARATIVO DE Argentina y Estados Unidos
}

\author{
Facundo Barrera* y Emiliano López**
}

Fecha de recepción: 24 de abril de 2010. Fecha de aceptación: 15 de julio de 2010.

\begin{abstract}
RESUMEN
La forma concreta que toma el proceso de valorización del capital en los países periféricos se diferencia sustancialmente de lo que ocurre en las naciones centrales. Los estudios empíricos que pretendan dar cuenta de esas particularidades deben, a nuestro entender, comprender el ciclo del capital en cada país como una totalidad. En el presente trabajo, realizamos una estimación de las categorías marxianas a partir de las tablas de insumoproducto de Estados Unidos y Argentina para los años 1997 y 2004. Dicha estimación nos permitirá realizar una comparación detallada de la totalidad de los momentos del ciclo del capital en una economía central y una periférica, otorgando un marco metodológicamente consistente para la aplicación empírica de las categorías analíticas. Los resultados obtenidos de la comparación de cada categoría nos permiten concluir que existen diferencias estructurales entre Estados Unidos y Argentina en cada momento del ciclo de valorización del capital.
\end{abstract}

\section{PALABRAS CLAVE}

Categorías marxianas, ciclo del capital, tablas insumo-producto, Argentina, Estados Unidos.

\footnotetext{
* Licenciado en Economía, Universidad Nacional de la Plata (UNLP), especialista en Economía Política por la Facultad Latinoamericana de Ciencias Sociales (Flacso). Centro de Estudios para el Cambio Social. Correo electrónico: facunbarrera@yahoo.com

** Licenciado en Economía / Doctorando en Ciencias Sociales por la Universidad de Buenos Aires (UBA); Centro de Estudios e Investigaciones Laborales-Programa de Investigaciones Económicas sobre Tecnología, Trabajo y Empleo (CEIL-PIETTE) del Consejo Nacional de Investigaciones Científicas y Técnicas (Conicet). Centro de Estudios para el Cambio Social. Correo electrónico: emiliano_lopez@speedy.com.ar
} 


\begin{abstract}
The concrete way in which the process of the valorization of capital occurs in the periphery countries differs substantially from what happens in the core nations. Empirical studies aimed at taking account of these particularities should, in our view, comprise the cycle of capital in each country as a whole. In the present work, we make an estimate of the Marxist categories based on input-output tables for the United States and Argentina for the period 1997-2004. This estimate enables us to carry out a detailed comparison of all of the moments in the capital cycle of a core and a periphery economy, providing a methodologically consistent framework for empirical application of the analytical categories. The results obtained from comparing each category allow us to conclude that structural differences exist between the United States and Argentina at each moment of the cycle of the valorization of capital.
\end{abstract}

Key terms: Marxist categories, capital cycle, input-output tables, Argentina, United States.

\title{
Résumé
}

La forme adéquate que prend le processus de mise en valeur du capital dans les pays périphériques se distingue substantiellement de ce qui se passe dans les nations centrales. Les études empiriques qui prétendent rendre compte de ces particularités doivent, selon nous, comprendre le cycle du capital dans chaque pays comme une totalité. Dans ce travail, nous réalisons une estimation des catégories marxiennes à partir des tableaux produit/facteurs de production en ce qui concerne les États-Unis et l'Argentine pour les années 1997 et 2004. Cette estimation nous permettra de réaliser une comparaison détaillée de la totalité des moments du cycle du capital dans une économie centrale et dans une économie périphérique, offrant un cadre méthodologiquement consistant pour l'application empirique des catégories analytiques. Les résultats obtenus de la comparaison de chaque catégorie nous permettent de conclure qu'il existe des différences structurelles entre les États-Unis et l'Argentine à chaque moment du cycle de mise en valeur du capital.

Mots clefs: catégories marxiennes, cycle du capital, tableaux facteurs de production produit, Argentine, États-Unis.

\section{Resumo}

A forma concreta que toma o processo de valorização do capital nos países periféricos se diferencia substancialmente do que ocorre nas nações centrais. Os estudos empíricos que pretendem dar conta destas peculiaridades devem, a nosso entender, compreender o ciclo do capital em cada país como uma totalidade. No presente trabalho, realizamos uma estimação das categorias marxianas a partir das tabelas de insumo-produto de Estados Unidos e Argentina para os anos 1997 e 2004. Esta estimação nos permite realizar uma comparação detalhada da totalidade dos momentos do ciclo do capital de uma economia central e de uma economia periférica, propiciando um marco metodologicamente consistente para a aplicação empírica das categorias analíticas. Os resultados obtidos a partir da comparaçáo de cada categoria nos permitem concluir que existem diferenças estruturais entre Estados Unidos e Argentina em cada momento do ciclo de valorização do capital.

Palavras-chave: categorias marxianas, ciclo do capital, tabelas insumo-produto, Argentina, Estados Unidos.

\section{利用投入产出表估算马克思主义两大部类：对阿根廷与美国的比较分析 “外围”国家的资本增值过程的具体方法与“中心”国家有极大的不同。 我们认为, 利用这些特殊性的实证研究应当包括每个国家作为一个整体的 资本循环。我们目前的工作就是要对1997-2004年期间的美国与阿根廷的 情况，作出一个基于投入产出表之上的马克思主义两大部类的估算。这个 估算能够对“中心和“外围”经济中资本循环的运动作出一个详细的比 较, 并为分析实证应用提供一个与之相一致方法论。通过比较每个部类所 获得的结果使我们得出结论：美国与阿根廷的资本增值循环的每个时点都 存在结构性差异。 \\ 关键词：马克思主义两大部类 资本循环 投入产出表 阿根廷 美国}




\section{INTRODUCCIÓN}

La forma concreta que toma el proceso de valorización del capital en los países periféricos se diferencia de lo que ocurre en los países centrales. Los estudios empíricos que pretendan dar cuenta de esas particularidades deben, a nuestro entender, comprender el ciclo del capital en cada país como una totalidad histórica concreta. Desde esta perspectiva, la producción y reproducción de la vida material en la periferia, bajo su posición subordinada al ciclo del capital a escala internacional, poseen características diferenciales respecto de las economías del centro. Asimismo, la manera en la cual circulan las mercancías creadas y los patrones de demanda final, se ven condicionados por el proceso de producción. La demanda final, a su vez, se relaciona con la producción de valor de manera dialéctica. Es decir, la dinámica del ciclo del capital en la periferia requiere del estudio en conjunto de las diferentes esferas de la economía doméstica, reconociendo su subordinación a la valorización del capital a escala global.

Numerosos trabajos se han encargado de estudiar el desenvolvimiento macroeconómico de la Argentina desde la instauración del régimen de convertibilidad del peso (1991) hasta nuestros días (Bisang, 1998; Heymann, 2000; Frenkel y Rapetti, 2007; Schorr, 2006). Sin embargo, la mayoría de ellos se realizan utilizando sin mediación las estadísticas oficiales que son construidas bajo los preceptos keynesiano-ortodoxos. Por ello, creemos necesario realizar una reinterpretación de las tablas de insumo-producto desde una perspectiva marxiana,${ }^{1}$ que permita una aproximación metodológica coherente con las particularidades de la economía argentina en tanto periférica y dependiente.

Por lo dicho, el presente trabajo intentará destacar las particularidades del ciclo de valorización en Argentina por medio del contraste con las características presentes en un país central (Estados Unidos). La reelaboración de las tablas de insumo-producto ortodoxas de Argentina y Estados Unidos para los años 1997 y 2004, mediante la aplicación de una clasificación de los trabajos productivo e improductivo para el capital, nos permitirá establecer una comparación detallada de las principales categorías marxianas en cada momento del ciclo del capital. Las tablas de insumo-producto son una fuente generalmente sub-valorada, que posee una gran riqueza de información y será complementada con otras que permitan evaluar cada una de las categorías de interés. La elección de los años de referencia busca destacar que existen en cada país, más allá de las fluctuaciones de la producción y del éxito o fracaso en la valorización/acumulación, características estructuralmente distintivas.

En la siguiente sección, discutiremos el enfoque teórico utilizado como marco de la elaboración empírica y, a su vez, plantearemos la importancia metodológica de reexpresar

\footnotetext{
Conscientemente hablamos de concepción marxiana y no de concepción marxista. El término marxiano hace referencia a los textos escritos por el propio Karl Marx y, por ende, refiere más directamente a nuestra interpretación económica de aquellos textos. Mientras que marxista se vincula mayormente con la(s) corriente(s) teórica(s) y política(s) que siguió a su muerte.
} 
las estadísticas oficiales para lograr una interpretación coherente con el marco teórico marxiano. A continuación, presentaremos una explicación acabada de la transformación de las cuentas ortodoxas para la medición de las categorías marxianas, las cuales serán empleadas en el análisis empírico. Una vez transformadas las tablas de insumo-producto de Estados Unidos y de Argentina, realizaremos la comparación para los ańos seleccionados, realzando las características diferenciales de los países central y el periférico. Finalmente, en la cuarta y última sección buscaremos destacar los principales resultados obtenidos y expondremos algunas conclusiones preliminares de la investigación.

\section{UN MARCO TEÓRICO Y METODOLÓGICO PARA EL ESTUDIO DE LA VALORIZACIÓN DEL CAPITAL}

El capital, como relación social dominante, puede describirse como un ciclo $(D-M-\ldots P \ldots$ $\left.-M^{\prime}-D\right)$ que comienza con un desembolso de capital en su forma dinero ( $D$ inicial) para la compra de mercancías $(M)$ a utilizarse en el proceso productivo $(M-\ldots-P-\ldots-M)$ y que concluye con una fase de circulación final $\left(M^{\prime}-D\right)$ en la cual se realizan las nuevas mercancías producidas. El ciclo completo tiene por objeto la propia valorización del capital (lograr que $D^{\prime}>D$ ). En ese sentido, debemos comprender la manera en la cual la lógica inmanente del capital produce (y reproduce) una mediación a todos los aspectos de la esfera social (Mészáros, 1995). La distribución del producto social, la dinámica del empleo de la fuerza de trabajo y hasta las relaciones del hombre con la naturaleza tienden a estar dominadas por la lógica inmanente del capital y, por tanto, ligados a su deber ser, que no es más que la generación de un excedente económico (plusvalor) mediante la apropiación privada de una porción del valor socialmente generado. Esto significa que es necesario estudiar el capital como una totalidad entre las esferas de la circulación, la producción y la distribución del producto social (Marx, 2007a). En ese sentido, es posible utilizar las categorías propuestas por Marx en El Capital para analizar el proceso por el cual se produce y reproduce el ciclo descrito.

Sin embargo, debemos tener presentes algunos aspectos metodológicos clave para la aplicación empírica de las categorías marxianas.

En primer lugar, una cuestión metodológica no menor a los fines del trabajo es que entendemos el estudio del ciclo del capital como una totalidad histórica concreta. En el análisis de los Elementos fundamentales para la crítica de la economía política (Grundrisse) de 1857-58, Marx desarrolla algunos de los puntos clave de la metodología que utilizará en su investigación sobre la dinámica del capital como relación social dominante. Partiendo del campo de la experiencia, el investigador sólo obtiene una representación caótica de lo real, por lo tanto abstracta. ${ }^{2}$ Por ello, la experiencia es sólo el punto de

2 Marx, haciendo alusión al método de la economía política y ejemplificando con el concepto que comienza el análisis de los economistas clásicos, plantea: "Si comenzara, pues, por la población tendría una representación caótica del conjunto y, precisando cada vez más, llegaría analíticamente a conceptos cada vez más simples: de lo concreto representado, llegarían abstracciones cada vez más sutiles hasta alcanzar las determinaciones más simples” (Marx, 2007:21). 
partida para la investigación de la sociedad, pero es insuficiente para conocer su esencia. Para dar cuenta de las especificidades del capitalismo en general y, del capitalismo periférico en particular, es necesario abstraerse de la experiencia para luego volver hacia ella con un esquema de pensamiento con múltiples determinaciones. Es decir, obtenemos por medio de la abstracción una serie de categorías aplicables a la realidad que se nos presenta, a priori, como caótica. Dussel (2004) señala que este paso involucra la construcción dialéctica de la totalidad de relaciones abstractas (determinaciones) que se construyeron previamente. Es decir, ponen en relación los conceptos que se desarrollaron y dicha relación es codeterminante entre dichos términos. Este nivel de determinaciones abstractas es el que desarrollaremos en el parágrafo siguiente, donde cada categoría cumple un rol (en abstracto) para dar cuenta del ciclo del capital.

En este punto se construye una nueva totalidad (ya no caótica, sino comprensible), conformada por la síntesis de las diferentes determinaciones que se hallaron mediante la abstracción (en nuestro caso, el ciclo del capital en general y los indicadores en abstracto que permiten evaluar las relaciones entre la esfera de la producción, la circulación y la distribución). Esta totalidad tiene ahora autonomía, es una unidad de múltiples determinaciones que antes aparecían como opuestas. De esta manera: "La totalidad concreta es lo complejo. Lo simple es la determinación, como el trabajo, la división del trabajo, la necesidad, el valor de cambio. Con todas ellas, dialécticamente, se asciende hasta las totalidades concretas" (Dussel, 2004:53).

Una vez en este nivel, es necesario descender desde la totalidad concreta construida por el investigador a una totalidad concreta histórica. En este paso de regreso a "lo real" toman su rol predominante las categorías explicativas y su orden. La totalidad concreta necesita de la mediación de cada una de las categorías explicativas para llegar a una totalidad histórica concreta. La totalidad histórica concreta es, por tanto, más compleja que la simple experiencia, pues posee mayores determinaciones y es, a su vez, conocida y explicada (Dussel, 2004). ${ }^{3}$

\section{Las categorías analíticas para el estudio del ciclo del capital en general}

A partir de estas premisas metodológicas, nos es posible presentar el análisis del capital en general (la totalidad concreta), para luego intentar un pasaje hacia lo "concreto real" mediante estas categorías.

\footnotetext{
Para clarificar este punto, es importante considerar que en el tomo I de El Capital Marx parte de la determinación más simple y, por tanto, más abstracta: la mercancía. De allí va operando dialécticamente por medio de las diversas determinaciones simples (y contradictorias) hasta alcanzar una totalidad concreta (pero a la vez abstracta en términos históricos): el capital en general. Sólo cuando se ha logrado describir esta serie de determinaciones complejas considera posible, en el capítulo XXIV del tomo I, comenzar a utilizar dicha totalidad para comprender el surgimiento histórico real del modo de producción capitalista: la llamada acumulación originaria (Marx, 2005b). Esta estructura de El Capital tiene que ver, como señala Godelier (1970), con que el método de exposición de Marx difiere del suyo. En El Capital está partiendo, al igual que Hegel en su Lógica, del primer nivel de abstracción: las determinaciones simples.
} 
El punto de partida del ciclo $D-M-\ldots P \ldots-M^{\prime}-D^{\prime}$-bajo una dinámica de reproducción ampliada- es, como hemos mencionado, el gasto de capital en su forma dinero para la compra de las mercancías utilizadas en el proceso productivo, entre las cuales se destacan las materias primas, los medios de producción y la fuerza de trabajo.

En segunda instancia, es por medio del proceso de producción (etapa $M-\ldots P$.. $-M^{\prime}$ ' del ciclo) que estas mercancías se subsumen al capital, generando un valor social total $(V T)$ que se encontrará conformado por el capital variable $(V)$, el capital constante circulante $(C C)$ y el plusvalor $(S)$. Así, el trabajo vivo no sólo genera una porción de valor suficiente para cubrir los costos de las materias primas y la depreciación de las maquinarias, sino que genera un nuevo valor (o valor agregado) que se distribuirá entre el pago a la fuerza de trabajo y el plusvalor. De esta manera, es en el proceso de producción donde se generan las relaciones sociales clave que el capital impone y, por tanto, donde se produce la valorización (la generación de $S$ ). Como afirma Marx: "El misterio de la virtud del capital para valorizarse a sí mismo tiene su clave en el poder de disposición sobre una determinada cantidad de trabajo ajeno no retribuido" (Marx, 2003:649). Es decir, el capital logra valorizarse si es capaz de subordinar a su lógica, a la actividad generadora de valor. ${ }^{4}$

El tercer momento del ciclo se caracteriza por una nueva etapa de circulación que está asociada a la venta del valor generado en el proceso de producción (expresado en la forma mercancía), a cambio de capital en su forma dineraria. ${ }^{5}$ En este punto debemos observar que existe una consistencia entre las etapas de circulación inicial $(D-M)$, de producción $(M-\ldots P \ldots-M)$ y de circulación final $\left(M^{\prime}-D\right)$. El valor total generado $(V T)$ en el proceso de producción no es más que una lectura desde el punto de vista de los ingresos. Sin embargo, siguiendo a Shaikh y Tonak (1994), la expresión de este valor materializado en mercancías se presenta como bienes y servicios (productos del trabajo), que llamaremos $P T$, cuya magnitud debe igualar al valor total (VT) para que exista una consistencia entre las esferas presentadas, es decir, entre la producción, la distribución y la circulación de mercancías. ${ }^{6}$ Dada dicha consistencia entre los productos del trabajo y los ingresos generados en el proceso de producción, es posible indagar acerca de los efectos codeterminantes que cada etapa del ciclo del capital tiene sobre las otras. Sin embargo, debemos reconocer que es el proceso de producción y reproducción del valor generado (por medio de la subsunción del trabajo al capital) lo que hace que una economía en particular posea características eminentemente capitalistas (Marini, 1979).

4 Como señala Dussel (2004) el trabajo (al igual que la producción de bienes y servicios) es, en principio, externo al deber ser del capital. La clave radica en que la lógica totalizadora del capital produce y reproduce las relaciones de dominación que le son convenientes, coaccionando al trabajador libre a participar en el proceso productivo como única alternativa para reproducir su propia vida.

5 En el marco de esta dinámica, también es posible que existan problemas para la realización de las mercancías, que surgen de las propias contradicciones de la valorización capitalista.

6 Este punto será profundizado en el siguiente apartado, cuando se discutan las categorías utilizadas empíricamente. 
Aquí es donde se plantea la necesidad de estudiar ciertas categorías analíticas que operan como indicadores, cualitativos y cuantitativos, del éxito de cada una de las etapas del ciclo del capital. En lo que respecta a la etapa inicial del ciclo, una de las categorías relevantes para la medición empírica es la relación entre la fuerza de trabajo vivo $(L)$ y el trabajo muerto $(C)$ incorporados en la producción, que puede definirse como la composición orgánica del capital (COC):

$C O C=\frac{C}{L}$

La estimación de la $C O C$ supone comprenderla como concepto mediador entre la composición técnica del capital (CTC) y la composición en valor $(C V C)$. La COC no es más que la manifestación de la CTC (la relación capital-trabajo de acuerdo con los conceptos de la economía ortodoxa). De allí que pueda estimarse como un cociente entre el capital constante ${ }^{7}$ en términos reales y la masa de trabajo vivo aplicada a la producción (Saad-Filho, 1993). Este indicador nos permite dar cuenta del proceso de intensificación del cambio técnico, fomentado por la competencia intercapitalista, que se encuentra detrás de la tendencia a la crisis en las economías dominadas por el capital (Marx, 2006). ${ }^{8}$

Las proporciones de trabajo vivo y medios de producción que se utilizan en el proceso productivo y se aplican sobre las materias primas, dan como resultado el valor total (que incluye el nuevo valor generado o el agregado). Es posible evaluar este proceso mediante el indicador llamado tasa de plusvalor, que se define como la proporción de plusvalor respecto de la retribución que reciben los trabajadores por la venta de su capacidad de trabajar (fuerza de trabajo):

\section{Tasa Plusvalor $=\stackrel{s}{\bar{v}}$}

Por ello, la tasa de plusvalor indica la manera en la cual se distribuye (primariamente) el ingreso entre la retribución a los productores directos y el excedente que éstos mismos generan. Esta categoría resulta relevante para el análisis del éxito de la valorización del capital.

\footnotetext{
El capital constante total es definido aquí como $C=C F+C C$, donde $C F$ es el capital fijo (stock de maquinarias, planta y equipo) y $C C$ la parte circulante del capital, es decir, aquel que se consume en el mismo proceso de producción (materiales y materias primas, por ejemplo).

8 Como es sabido, la acumulación involucra un proceso de mecanización o desplazamiento de fuerza de trabajo vivo por trabajo muerto (maquinaria). En términos de valor, ese proceso tiende a incrementar la masa de valor que no produce plusvalor en detrimento de aquélla que sí lo hace, generando así una presión a la caída en la tasa de ganancia. En tanto este proceso es producto de la reproducción del ciclo del capital (por ello inmanente a la reproducción capitalista) es una tendencia dominante. Este movimiento enfrenta en la crisis los medios para su propia superación: positiva, en tanto reestructuración de las relaciones capitalistas y reajuste de las relaciones básicas del capital o bien negativa, en tanto el capital puede ser superado como relación social dominante (Lebowitz, 1976).
} 
Por otra parte, cierta composición orgánica del capital configura determinada fuerza productiva del trabajo (FPT), que podemos definir, para la economía en su conjunto, como la relación entre el producto total generado y la fuerza de trabajo viva empleada en la producción:

$F P T=\frac{P T}{L}$

Este indicador también permite relacionar un aspecto de la fase inicial de circulación con la fase de producción en el ciclo de valorización. Esto es, el efecto que posee la composición del capital sobre la cantidad de bienes físicos producidos, así como también cierta forma de extracción de plusvalor. La evolución relativa de dicha capacidad productiva del trabajo y del capital variable permite dar cuenta de la estrategia de extracción de plusvalor seguida por el capital en su conjunto (Lebowitz, 2005).?

Por último, es necesario discutir acerca de la realización del valor generado en el proceso productivo y la capacidad de acumulación en un espacio de valor específico. Para ello, debemos observar algunas variables relevantes de la esfera de la circulación en la tercera fase del ciclo. En ese sentido, resulta útil evaluar la tasa de ganancia de la economía en su conjunto $(T G)$, o tasa general de ganancia. Siguiendo los desarrollos de Marx (2006), la misma se define como el cociente entre el plusvalor y el capital total adelantado para la producción (constante y variable). Algebráicamente, la tasa de ganancia puede expresarse como:

$\pi=\frac{S}{C+V}$

Por otra parte, la capacidad de acumulación de una economía capitalista se encuentra asociada a las proporciones del producto final $(P F)^{10}$ que se destinan a la inversión en capital fijo $(l),{ }^{11} l$ al consumo suntuario $\left(C O N_{K}\right)$ y a las exportaciones netas $(X-M)$. Asimismo, incluiremos como indicadores las participaciones del consumo de los trabajadores $\left(C O N_{W}\right)$ y del Estado $(G)$ en el producto final. Los indicadores que emplearemos para el estudio de este aspecto del proceso de acumulación serán:

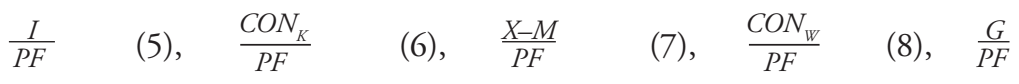

\footnotetext{
9 En ese sentido, una tasa de crecimiento positiva para ambas variables y una mayor aceleración relativa de la fuerza productiva del trabajo implicaría, ceteris paribus, que la estrategia más extendida de extracción de plusvalor es una basada en el cambio técnico (plusvalor relativo). Por el contrario, una estrategia de plusvalor absoluto se presentará como dominante cuando los incrementos de la productividad del trabajo no se vean acompańados por aumentos del capital variable.

10 El producto final $(P F)$ se define aquí como el $P T$ menos el consumo intermedio.

11 La inversión en capital fijo y el capital fijo utilizado para el cálculo de la tasa de ganancia son conceptos diferentes. Mientras que el primero se relaciona con el stock de capital adelantado al inicio del ciclo, la inversión en capital fijo es una parte del valor plusvalor generado que se destina a incrementar dicho stock de capital inicial, es por ello un flujo.
} 
Estas categorías representan los usos del producto que se ha generado en un ciclo completo del capital. La tendencia a la expansión permanente en las economías dominadas por el capital necesita de la inversión en capital fijo para incrementar la fuerza productiva del trabajo. Por ello, aquellas economías (como totalidades históricas concretas) en las cuales la proporción del valor producido que se destina al consumo productivo es superior, poseerán mayores potencialidades de acumulación de capital y, por tanto, posibilidades crecientes de valorización futura. Por el contrario, altas proporciones de consumo suntuario y transferencias de valor al exterior (mediante exportaciones netas), podrían traducirse en una dinámica de acumulación menos virtuosa. ${ }^{12}$

Las variables aquí propuestas nos serán de gran utilidad para la evaluación de las características diferenciales del ciclo del capital en la economía argentina, en tanto periférica, en oposición a una economía central como la estadounidense. Numerosos estudios empíricos se han realizado en diferentes países con categorías similares a las que proponemos aquí: para Estados Unidos pueden verse los trabajos de Shaikh y Tonak (1994), Moseley (1985; 1997) y Wolf (2001); para Gran Bretaña, el estudio de Cockshott, Cotrell y Michaelson (1995); para la economía griega, el de Maniatis (2005); para Filipinas, el de Venida (2007), entre otros. Sin embargo, esta línea de investigación ha sido dejada de lado en Argentina, donde la mayoría de los estudios macroeconómicos se corresponden con visiones vinculadas a corrientes keynesianas u ortodoxas de la economía. Por ello, creemos relevante avanzar en una caracterización de Argentina como país periférico basándonos en las categorías propuestas en el presente trabajo, pues nos permiten un estudio más riguroso de la unidad formada por las tres esferas mencionadas, teniendo en cuenta que en las sociedades dominadas por el capital las relaciones de producción son las que le dan su carácter específico.

La lógica del capital que hemos descrito en el presente apartado es válida para el análisis abstracto (general). Sin embargo, para realizar una aproximación a los fenómenos que pretendemos estudiar deben concretarse aún más las categorías propuestas.

\section{Trabajo productivo e improductivo: la necesaria reexpresión de las cuentas ortodoxas}

Como hemos comentado previamente, la aplicación de categorías teóricas sin mediación alguna a la experiencia puede provocar, en ocasiones, errores de interpretación de la realidad. Por ello, el sistema de relaciones desarrollado por Marx necesita de una serie de mediaciones para llevar a cabo análisis empíricos. Las categorías marxianas no pueden obtenerse simplemente por medio de una relectura de los conceptos tal y como aparecen en las tablas de insumo-producto en particular, pues dichos conceptos no dan

12 Marini (1979) destaca este fenómeno de incapacidad de acumulación virtuosa en las economías latinoamericanas con base en un análisis de los esquemas de Marx. 
cuenta con precisión de la perspectiva teórica que adoptamos aquí. Las tablas de insumo-producto ortodoxas no son teóricamente neutrales, por lo que resulta de gran relevancia su redefinición si se pretende realizar un estudio desde una perspectiva centrada en la teoría del valor y la explotación de Marx.

El punto de partida de un análisis alternativo de dichas tablas requiere introducir brevemente la discusión acerca del trabajo productivo e improductivo en las sociedades dominadas por el capital. El debate en torno del carácter productivo o improductivo del trabajo humano no se encuentra exento de controversias teóricas. En la obra de Marx, el trabajo humano, como actividad creadora de valor, es analizada al menos en dos niveles de abstracción: el trabajo humano en general (más allá de las relaciones sociales dominantes) y el trabajo bajo el dominio del capital.

En primer lugar, el trabajo es para Marx una actividad eminentemente humana capaz de transformar la naturaleza y obtener, por medio de un proceso de producción, valores de uso (Marx, 2005). Más allá de las formas concretas en que se manifiesta la riqueza producida y de las relaciones sociales implicadas en la producción, podríamos decir que el trabajo en general implica la generación de valores tales que sean útiles para la satisfacción de necesidades sociales. Es éste un carácter esencial del trabajo, en cuanto que no se encuentra determinado por la forma de organización social de la producción. A este nivel de abstracción, el trabajo será productivo, siempre que genere nueva riqueza social, es decir, nuevos valores de uso (Bidet, 2007; Savran y Tonak, 1999).

Sin embargo, y siendo consecuentes con el planteamiento metodológico previo, es necesario descender a niveles de abstracción menores y, por tanto, encontrar nuevas determinaciones. El trabajo humano en las sociedades dominadas por el capital aparece, principalmente, como trabajo asalariado. Los productos del trabajo se manifiestan como mercancías y el orden lógico de las categorías se reorienta hacia la producción de plusvalor. ${ }^{13}$ Es en este punto que toma relevancia la noción de trabajo productivo para el capital, es decir, trabajo que mediante el proceso de producción permite la valorización del capital. Siguiendo a Marx: "trabajo productivo, en su significado para la producción capitalista, es trabajo asalariado que, cambiado por la parte variable del capital (la parte del capital que se destina a salarios), reproduce no sólo dicha parte del capital sino que además produce plusvalía para el capitalista” (Marx, 1974:129). De esa manera, el trabajo sólo será productivo para el capital si tiende a generar un ciclo de valorización exitoso. ${ }^{14}$ Por lo tanto, la creación de valor de uso en sí misma no es el deber ser de la producción bajo el capital, sino que este rol lo cumple la producción de valor/plusvalor.

En lo que respecta a este último punto, es posible encontrar acuerdo en una multiplicidad de autores en cuanto a que el trabajo productivo para el capital es aquel que

13 Como señala Dussel (2004) en su estudio sobre los Grundrisse, éste es el proceso por el cual las distintas categorías abstractas (trabajo, productos del trabajo, dinero, entre otros) se subsumen a la lógica del capital.

14 Contrariamente, el trabajo improductivo para el capital se encontrará asociado así a actividades de producción autogestiva, al trabajo doméstico, a las actividades de servicio social, entre otras. 
permite valorizarlo por medio del ciclo $D-M-\ldots P \ldots-M^{\prime}$ - $D^{\prime}$ (Shaikh y Tonak, 1994; Savran y Tonak, 1999; Cámara Izquierdo, 2006). Sin embargo, existe una discrepancia teórica de importancia entre algunos de estos autores, que es necesario mencionar brevemente. El eje del debate se encuentra en cómo articular el nivel de abstracción más general (trabajo generador de valores de uso) con el nivel propio de la sociedad dominada por el capital. Cámara Izquierdo (2006), tomando estrictamente la especificidad del trabajo desde la lógica del capital para determinar su carácter productivo o improductivo, sostiene que en el capitalismo es la producción de valor y, por tanto, el trabajo abstractamente humano el que debe considerarse como productivo. Es decir, la necesidad del capital de valorizarse requiere de la generación de valores y no de valores de uso que serían útiles para la satisfacción de necesidades sociales. ${ }^{15}$ Desde esta perspectiva sólo debe considerarse como productivo el trabajo que se emplea en la producción de plusvalor.

Por su parte, y sin descartar la especificidad del trabajo y la producción bajo el capital, tanto Shaikh y Tonak (1994) como Savran y Tonak (1999) desarrollan un criterio según el cual el trabajo productivo para el capital no sólo está asociado a la producción (y reproducción) de plusvalor, sino también a la producción y reproducción de nuevos valores de uso, es decir, a trabajo que es considerado socialmente necesario pero que se expresa como trabajo concreto.

Si bien no es objeto del presente artículo resolver la discusión aquí planteada, en definitiva creemos que es posible entender que ambos niveles de abstracción no se niegan completamente. De esa manera, si bien la creación de valores de uso (la aplicación de trabajo concreto) no es la lógica predominante del capital en general, el trabajo abstractamente humano se expresa en formas de trabajo concreto. Para el análisis empírico es muy improbable que se pueda realizar una separación adecuada entre valores y valores de uso de la mercancía y entre trabajo abstracto y trabajo concreto. Por lo tanto, una manifestación empírica del valor, como contrapartida del trabajo productivo abstracto, puede encontrarse en el trabajo productivo concreto y los valores de uso que el mismo produce y reproduce. De esta manera, en el descenso de lo abstracto a lo concreto, creemos que es posible utilizar el esquema que plantean Savran y Tonak (1999), y Shaikh y Tonak (1994) para lograr un análisis comparativo entre el ciclo del capital en el centro y en la periferia, mediante una unidad entre las esferas de la producción y la circulación-distribución.

Así, siguiendo el esquema presentado por Savran y Tonak (1999), consideramos cinco tipos de actividades laborales esenciales en la sociedad dominada por el capital: a) producción, b) circulación, c) distribución, d) consumo social y personal y e) reproducción del orden social. De estas actividades pueden considerarse productivas para el capital sólo la producción, la circulación y la reproducción del orden social (poder de policía, administración pública, entre otras), mientras que las actividades asociadas a la distribución del ingreso y el consumo social y personal no serán productivas en términos

15 Véase Marx (2005:43-87), donde se plantea la discusión en lo que respecta a la dualidad del trabajo y la de las mercancías. 
de la obtención de plusvalor. Sin embargo, sólo se considera como productivo, en términos de generación de nuevos valores de uso, el trabajo destinado a las actividades de producción. De esa manera, sólo será productivo en el doble sentido aquí planteado, el trabajo asalariado (en relación capitalista) que esté asociado a las actividades de creación de nuevos bienes y servicios. El resto de los trabajos concretos pueden, sin duda, tener su relevancia social, pero se encontrarán subordinados en términos de la reproducción material a esta actividad primaria. La producción y reproducción de valor estará conformada principalmente por aquellas ramas de actividad ligadas a la producción, mientras que en el resto de los sectores (de circulación, finanzas, no capitalista, entre otras) se distribuirá parte del plusvalor no apropiado por los primeros (Shaihk y Tonak, 1994).

Estas definiciones nos permiten clasificar de manera general todas las actividades o ramas de actividad que se encuentran en las Cuentas Nacionales. La Figura 1 da cuenta de esta clasificación, que aplicaremos a las tablas de insumo-producto de Argentina y Estados Unidos.

Figura 1. Clasificación del trabajo productivo e improductivo para el capital

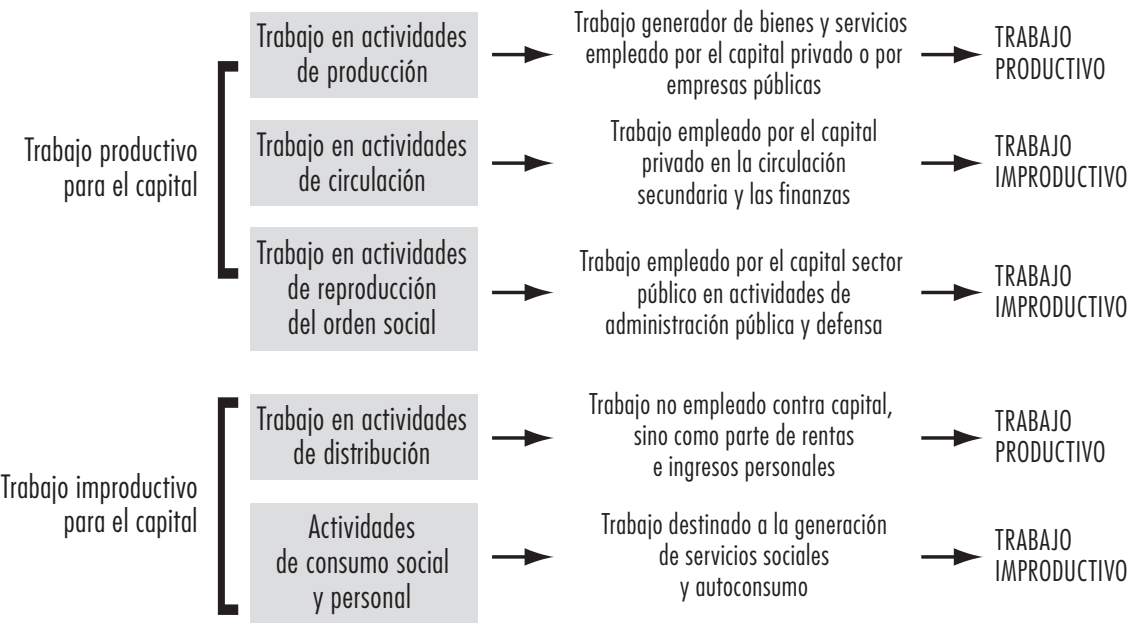

Fuente: elaboración propia con base en Savran y Tonak (1999).

El estudio empírico de las características del proceso de valorización en una economía concreta por medio de la metodología adoptada, deja de lado la sola interpretación fenoménica que en general adoptan numerosos enfoques ortodoxos y heterodoxos, en los cuales la esfera de la producción, que es el eje del proceso de valorización del capital, es completamente abandonada en pos de una interpretación "circulacionista" (Carcanholo, 2009). 


\section{LA REFORMULACIÓN DE LAS TABLAS DE INSUMO-PRODUCTO CON BASE EN LAS CATEGORÍAS MARXIANAS}

A partir de la clasificación de actividades productivas e improductivas para el capital que presentamos en la sección previa, avanzamos aquí en la redefinición de las tablas de insumo-producto, que miden la producción de riqueza material de un país. En el descenso dialéctico a la totalidad histórica concreta, creemos necesario compatibilizar las categorías de análisis que utilizamos en el plano abstracto con los datos que surgen del relevamiento empírico. De esa manera, se lleva a cabo una breve descripción de las tablas de insumo-producto de ambos países para luego adentrarnos en la reformulación con base en categorías marxianas. Una vez elaboradas, nos permitirán un acercamiento empírico coherente con nuestra perspectiva teórica.

\section{De las categorías ortodoxas a las marxianas}

Las tablas de insumo-producto (TIP) organizan las transacciones entre las diferentes actividades económicas y de cada actividad consigo misma (inter e intrarama). La información contenida allí ilustra la interrelación de los diversos sectores y los impactos directos e indirectos que puede tener sobre éstos una modificación de la demanda final. Así, las tablas permiten cuantificar el incremento de los ingresos generados en cada uno de los sectores de la economía (lado de los ingresos) y la manera en la cual estos ingresos son gastados (lado de los usos). Las TIP constituyen una gran herramienta para la investigación empírica, otorgando un marco de consistencia para las estimaciones que provienen de distintas fuentes: encuestas industriales, encuestas de gastos de los hogares, estadísticas de comercio exterior, entre otros (Indec, 2001). Por otra parte, las tablas dividen -siguiendo criterios ortodoxos- el valor agregado generado en cada sector, entre los ingresos de capitalistas y trabajadores asalariados, en cada periodo de referencia.

La reelaboración de las TIP se realizó tomando como referencia la aplicación empírica de Shaikh y Tonak (1994) para la economía estadounidense. Sin embargo, como hemos planteado en la sección anterior, las actividades económicas que consideramos productivas e improductivas difieren del desarrollo de estos autores en punto clave: el trabajo en las actividades comerciales (de circulación) lo consideraremos aquí no productivo. A nuestro entender, el comercio que emplea trabajo asalariado se inscribe en el proceso de circulación y realización del valor generado. El capital comercial apropia una parte del valor generado en la esfera de la producción en concepto de márgenes de comercialización.

Por lo dicho, la producción y reproducción del valor en el espacio doméstico sólo estará conformada por aquellas ramas de actividad que caracterizamos como creadoras de nuevos valores de uso y que, a su vez, persiguen la valorización. En el resto de las actividades se realizará y distribuirá parte del plusvalor no apropiado por los primeros. De 
esa manera, englobamos en la esfera de la producción a todas aquellas actividades que involucran trabajo productivo para el capital (generadoras de plusvalor) y que acrecientan o transforman las mercancías de uso social (valores de uso), es decir, producción de bienes y servicios; mientras que en la esfera de la circulación se incluyen aquellas actividades vinculadas con la realización (comercio minorista y mayorista) y la redistribución del valor originado en la primera esfera (finanzas, alquileres y ventas inmobiliarias). Este valor es redistribuido a partir de transferencias originadas en el pago de renta de la tierra, intereses, salarios, entre otros.

Por último, designamos como sector no capitalista a toda actividad en la cual no rige una lógica de extracción de plusvalor: servicios comunitarios, domésticos y actividades no empresariales del Estado. ${ }^{16}$

En síntesis, la principal divergencia entre las cuentas ortodoxas y marxianas surge del hecho de que para las primeras las actividades de la esfera circulación y el sector no capitalista son consideradas productivas, mientras que desde la perspectiva que adoptamos los ingresos de la segunda esfera se originan en la primera, es decir, los flujos secundarios son considerados parte del total de las transacciones (lado de los usos), pero no parte del valor total o producto total generado en la economía (lado de los ingresos).

En el Cuadro 1, que expresa las Tip de manera simplificada, se resume gráficamente esta diferencia. Las tablas de insumo-producto ortodoxas estarían contabilizando la totalidad de las actividades como productivas, por lo cual las sumas en el lado de los ingresos

Cuadro 1. Equivalencia de las tablas insumo-producto entre categorías marxianas y ortodoxas

\begin{tabular}{|c|c|c|c|c|c|c|c|c|c|}
\hline & $\begin{array}{l}\text { Produc- } \\
\text { ción }\end{array}$ & $\begin{array}{l}\text { Circu- } \\
\text { lación }\end{array}$ & $\begin{array}{l}\text { No Capi- } \\
\text { talista }\end{array}$ & CONw & $\mathrm{CONC}$ & 1 & X-IMPO & $G$ & PT \\
\hline Producción & Mp-p & Mp-c & Mp-nc & CONw-p & CONk-p & Ip & (X-Impo)p & $G p$ & $P T p$ \\
\hline Circulación & $M c-p$ & $M c-c$ & $M c-n c$ & $\underset{c}{\mathrm{CONW}-}$ & CONW-C & lc & (X-Impo)c & $G c$ & PTC \\
\hline $\begin{array}{l}\text { No Capi- } \\
\text { talista }\end{array}$ & Mnc-p & Mnc-c & Mnc-nc & $\begin{array}{c}\mathrm{CONW}_{\mathrm{n}}- \\
\text { ne }\end{array}$ & - & - & $(X-I m p o) n c$ & Gnc & PTnc \\
\hline M & $M p$ & $M c$ & Mnc & & & & & & \\
\hline $\begin{array}{l}\text { Impo + T } \\
\text { impo }\end{array}$ & $x x$ & $x x$ & $x x$ & & & & & & \\
\hline T nac & $x x$ & $x x$ & $x x$ & & & & & & \\
\hline
\end{tabular}

PT Producto
Mp- Capital constante circulante
Wi Masa salarial de cada
CONw Cosumo
I Gastos de inversión de cada
G Gastos de gobierno de cada
Fuente: elaboración propia con base en Shaikh y Tonak (1994)

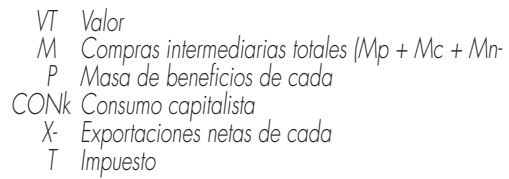

16 Cabe señalar que la intervención estatal en la economía no hace más que redistribuir valores ya generados, siempre y cuando no existan empresas públicas productoras de bienes y servicios, como es el caso de Argentina. Como veremos, no ocurre lo mismo en Estados Unidos. 
(filas) y en el lado de los usos (columnas) representarían el valor bruto de producción (VвP) y el producto total, respectivamente, de cada esfera. Para el total de la economía, simplemente se realiza la sumatoria de cada fila (columna). Desde la perspectiva marxiana, sólo las filas (columnas) sombreadas del Cuadro 1 se considerarán como productores y reproductores de valor en las TIP.

$\mathrm{Al}$ analizar la tabla por el lado de los ingresos, podemos extraer algunas diferencias clave entre las cuentas ortodoxas y las marxianas, en los dos momentos iniciales del ciclo del capital $(D-M-\ldots-P)$. El valor total $(V T)$ en términos marxianos $(V T=V T p)$ resultará siempre inferior al que surge de las tablas de insumo-producto ortodoxas $(V B P=$ $V T p+V T c+V T n c)$. Asimismo, en el primer caso el valor agregado $(V A)$ se obtiene al deducirle a $V T$ el capital constante circulante $(V A=V T-M p-p)$, por lo que también será inferior al que corresponde a las cuentas ortodoxas, en las cuales al $V B P$ se le deduce la totalidad de las compras intermedias $(V A=V B P-M)$. Por su parte, el capital variable $(V)$ será equivalente a la masa salarial de la esfera productiva $(W p)$. Por último, el plusvalor $(S=V A-V)$ se obtiene de la diferencia entre el $V A$ y $V$. Este concepto posee una correspondencia con el excedente bruto de explotación (EBE) calculado en las TIP oficiales. El plusvalor será evidentemente mayor al EBE.

Al observar el lado de los usos podemos encontrar las diferencias en el tercer momento del ciclo del capital $\left(M^{\prime}-D\right)$. Por parte de la ortodoxia, el $P T$ equivale a la suma de las compras intermedias $(M)$ y el producto final $(P F)$ para el conjunto de las esferas (circulación, producción y sector no capitalistas). Este último no es más que la sumatoria de los distintos destinos de la producción: $P F=C o n w+C o n k+I+(X-I M P O)+G$. En cuanto a la equivalencia marxiana, el $P T$ incluye sólo aquellas variables propias de la esfera de la producción $(P T p)$, mientras que para hallar el $P F$ debemos deducir el consumo intermedio correspondiente exclusivamente a estas actividades $(P F=P T p-M p p)$. De nuevo, el producto total desde la perspectiva marxiana será menor al que surge de las cuentas oficiales.

Por lo desarrollado hasta aquí, la reinterpretación de las TIP nos otorga un marco de consistencia del ciclo completo del capital que nos permite trabajar en aplicaciones empíricas que, creemos, resultan metodológicamente más adecuadas para la aplicación de categorías marxianas.

\section{Breve descripción de las fuentes utilizadas}

Para efectos de análisis de las características diferenciales del ciclo del capital en el centro y la periferia, transformamos las tablas de insumo-producto de Estados Unidos y Argentina con base en la clasificación de actividades en las que se lleva a cabo trabajo productivo e improductivo, para medir la producción de riqueza de esas naciones. Para ello, utilizamos la información publicada por el Bureau of Economic Análisis (BEA) y el Labor Bureau of Statistics (LBS) -dependientes del us Department of Commerce- y de la Dirección 
Nacional de Cuentas Nacionales- inserta en el Instituto Nacional de Estadística y Censos (Indec)-. Dado que nuestra intención es destacar fenómenos de carácter estructural, seleccionamos dos matrices por país que nos permitirán describir las similitudes y diferencias de la estructura de valorización del capital en los años 1997 y 2004.

En Estados Unidos (EU) las TIP son publicadas anualmente. El problema que surge para la caracterización del ciclo del capital en un marco de consistencia entre el lado de los ingresos y el lado de los usos, es que las tablas de Eu no son cuadradas (producto-por-producto o industria-por-industria), sino, por el contrario, rectangulares (industria-por-producto o producto-por-industria). Por ello, resultó necesario transformarlas en matrices cuadradas por medio del método de cuota de mercado. ${ }^{17}$ En el caso argentino la última publicación oficial de la matriz insumo producto (MIP) realizada por la Dirección Nacional de Cuentas Nacionales data de 1997. Por ende, para obtener las estadísticas referentes al consumo intermedio para Argentina en 2004, se realizó una actualización de la MIP de 1997 siguiendo la metodología planteada en el trabajo del Mecon (2007), el cual se basa en el método RAs. ${ }^{18}$

Por su parte, los datos referentes al empleo y la distribución del valor agregado entre asalariados y no asalariados para 2004 se obtuvieron, en el caso argentino, de la Cuenta Generación del Ingreso publicada para el periodo 1993-2007 por la Dirección Nacional de Cuentas Nacionales del Indec, que resulta compatible con los valores que surgen de las tablas de insumo-producto. En cuanto a Estados Unidos, los datos referentes al empleo y distribución del valor agregado se extrajeron de GDP by Industry va NAICS del BEA. Con la información surgida de estas cuentas, para la economía argentina se construyó la TIP marxiana a partir de una apertura de quince actividades económicas, mientras que para Estados Unidos se tomaron únicamente trece actividades. La clasificación de las actividades productivas e improductivas se presenta en el Cuadro 2.

Los valores incluidos en ambas matrices fueron expresados a precios constantes de 2000, a partir de diversos índices de precios de la producción. ${ }^{19}$ Luego, fueron

17 El método de cuota de mercado permite construir una matriz de producto-por-industria, como la que se obtiene del BEA, en una matriz de industria-por-industria. Para ello, se construyó una matriz $D t$ (transpuesta de $D$ ) de 12 filas y 16 columnas (para 1997) y una de 16 filas y 16 columnas (para 2004). Los elementos de la matriz $D$ representan la proporción en que cada producto es generado por cada industria. Luego, definimos las matrices $B$ como el cuadrante intermedio de la matriz de utilización $(16 \times 12$ y $16 \times 16$ para 1997 y 2004 , respectivamente) y $F$ como el cuadrante de demanda final de la tabla de insumo-producto de utilización $(16 \times 6$ para 1997 y 2004). Con estas matrices es posible construir la matriz simétrica como resultado de las multiplicaciones $D t \times B$ (matriz de insumos intermedios) y $D t \times F$ (matriz de demanda final). Para profundizar en el método, véase Indec (1997).

18 El método Ras básico fue desarrollado en el Departamento de Economía Aplicada de la Universidad de Cambridge (Reino Unido), por el Premio Nobel Richard Stone en los primeros años de la década de los sesenta. Este método es una traslación de la teoría de ajuste de matrices con restricciones hacia la estimación de matrices input-output. Este método indirecto permite reducir la información fuente requerida y proporciona estimaciones con resultados próximos a los métodos directos (Malizia y Bond, 1974; Pedreño, 1986).

En cada caso se utilizaron, para deflactar las compras intermedias de cada país, los índices de precios de productor propios de la actividad productiva en cuestión, tomando como base el mes de enero de 2000. Para el bloque de la demanda final se utilizaron los índices de precios del consumidor (IPC y CPI) de Argentina y EU con base en enero de $2000=100$, excepto para exportaciones e importaciones. Además, para los precios el capital fijo de Argentina se empleó un índice combinado de importaciones de bienes de capital y maquinarias de origen nacional. Todos los datos empleados aquí se encuentran disponibles en Indec y BEA. 
Cuadro 2. Clasificación de las actividades de las tablas de insumo-producto en productivo e improductivo, Argentina y Estados Unidos 1997-2004

\begin{tabular}{|c|c|c|}
\hline $\begin{array}{l}\text { Clasificación } \\
\text { marxiana }\end{array}$ & Actividades económicas en las tablas producto & $\begin{array}{c}\text { Actividades económicas en las tablas producto. } \\
\text { Estados }\end{array}$ \\
\hline \multirow{6}{*}{$\begin{array}{l}\text { Esfera de la } \\
\text { producción }\end{array}$} & Agricultura, ganadería, caza, silvicultura y pesca & Natural resources and mining \\
\hline & Minería & Manufacturing products \\
\hline & Industrias manufactureras & Construction \\
\hline & Construcción & Transportation and utilities \\
\hline & Suministros de electricidad, gas y agua & \\
\hline & Transporte y almacenamiento & \\
\hline \multirow{6}{*}{$\begin{array}{l}\text { Esferas de la } \\
\text { circulación }\end{array}$} & Comercio & Trade \\
\hline & Hoteles y restaurantes & Information \\
\hline & Correos y telecomunicaciones & Leisure and hospitality \\
\hline & Enseñanza y salud & Education and health services \\
\hline & Intermediación financiera & Financial services \\
\hline & $\begin{array}{l}\text { Actividades inmobiliarias, empresariales y de } \\
\text { alquiler }\end{array}$ & Profesional and business services \\
\hline \multirow{3}{*}{$\begin{array}{l}\text { Sector no } \\
\text { capitalista }\end{array}$} & Administración pública y defensa & Goverment \\
\hline & Actividades comunitarias, sociales y personales & Other services \\
\hline & Servicio doméstico & Other \\
\hline
\end{tabular}

Fuente: elaboración propia con base en datos de DNCN-Indec; BEA-USA.

transformados a moneda estadounidense (dólares) constante del año 2000. La elección de esa divisa como unidad monetaria en la que se expresan todos los valores merece una breve reflexión. Las relaciones sociales en el capitalismo se sustentan materialmente en la categoría de valor. De esta manera, todas las magnitudes que tienen una expresión en términos monetarios tienen su fundamento en el valor y las relaciones que lo sostienen. Dado que en el capitalismo contemporáneo el valor está ligado al ciclo del capital a escala global, creemos correcta la utilización de dólares estadounidenses como manifestación más concreta de dicho ciclo, pues esa moneda representa la unidad de cuenta de la mayoría de las transacciones económicas mundiales. Por otra parte, al tomar el dólar en términos constantes, quitamos el efecto de la inflación interna de los Estados Unidos, de manera que las pérdidas de poder adquisitivo de esa divisa no sean confundidas con cambios en el valor internacional (Féliz, López y Álvarez Hayes, 2010).

\section{Del cálculo de las categorías a la descripción del proceso de valorización en Argentina y Estados Unidos}

A partir de la información de las TiP de Argentina y Eu y la conversión en términos marxianos de dichas cuentas, presentamos los valores que adoptan las categorías que hemos 
definido como marco teórico para el estudio de cada momento del ciclo. Para ordenar la exposición, en primer lugar expondremos la magnitud de valor generada en cada año de referencia (1997-2004) y su conformación como capital variable (V), capital constante circulante $(C)^{20}$ y plusvalor $(S)$. La sumatoria de los mismos nos permite obtener el valor total $(V T)$. En segunda instancia, analizaremos mediante el correlato empírico de los indicadores de las ecuaciones (1)-(9), las diferencias más significativas en cada momento del ciclo del capital entre Argentina y Estados Unidos para los ańos seleccionados.

Como se evidencia en el Cuadro 3, el valor total generado en EU supera significativamente al de Argentina en ambos periodos. Mientras que en 1997 la diferencia en el VT del país central y el periférico era de 25 veces, en 2004, luego de que Argentina atravesara una recesión económica en el periodo 1998-2002 y se resolviera la crisis de valorización mediante la devaluación de su moneda, las diferencias en la producción de valor se acentuaron significativamente. El VT de Eu respecto al argentino fue 62 veces mayor.

El proceso de desvalorización generalizado de las mercancías que la devaluación del peso trajo aparejado, no impactó en la misma proporción en todos los componentes del $V T$. Por el contrario, el capital variable sufrió una caída muy superior respecto del capital circulante $(68 \%)$ y del plusvalor (71\%). Más allá de las diferencias en la magnitud del valor total entre la economía del centro y la economía periférica, es relevante destacar que el capital variable es el componente que tiene una brecha más amplia (33 y 130 veces superior en Estados Unidos que Argentina en 1997 y 2004, respectivamente).

Cuadro 3. Valor total, capital variable, capital constante y plusvalor en Argentina y Estados Unidos 1997-2004 Millones de dólares constantes de 2000

\begin{tabular}{lcccc}
\hline Países & Categorías & \multicolumn{1}{c}{1997} & \multicolumn{1}{c}{2004} & Variación \% \\
\hline \multirow{4}{*}{ Argentina } & V & $36,218,528$ & $10,435,174$ & $-71 \%$ \\
& $\mathrm{C}$ & $92,237,199$ & $29,691,249$ & $-68 \%$ \\
& $\mathrm{~S}$ & $99,234,550$ & $57,454,455$ & $-42 \%$ \\
& $V T$ & $227,690,278$ & $97,580,878$ & $-57 \%$ \\
\hline \multirow{3}{*}{ Estados Unidos } & $\mathrm{V}$ & $1,254,098,398$ & $1,414,670,790$ & $13 \%$ \\
& $\mathrm{C}$ & $2,512,641,591$ & $2,463,481,415$ & $-2 \%$ \\
& $\mathrm{~S}$ & $2,157,541,505$ & $2,362,388,774$ & $9 \%$ \\
& $V T$ & $5,924,281,494$ & $6,240,540,979$ & $5 \%$ \\
\hline
\end{tabular}

Fuente: elaboración propia con base en datos de Indec y BEA.

Asimismo, los cambios que se produjeron en el capital variable, circulante y en el plusvalor para cada uno de los países entre 1997 y 2004, resultaron en una composición muy diferente del valor total en cada una de las economías. Como se observa en la Figura

$20 \mathrm{Al}$ estar evaluando los flujos anuales, el capital constante se encuentra integrado por capital circulante, exclusivamente. 
2, la participación del plusvalor en el valor total se incrementó fuertemente en Argentina (35\%) en detrimento del capital variable (-25\%) y el capital circulante (-33\%). En Eu, por el contrario, la estructura del $V T$ no se vio modificada sustancialmente.

Figura 2. Estructura del valor total en Argentina y Estados Unidos. Años 1997 y 2004.

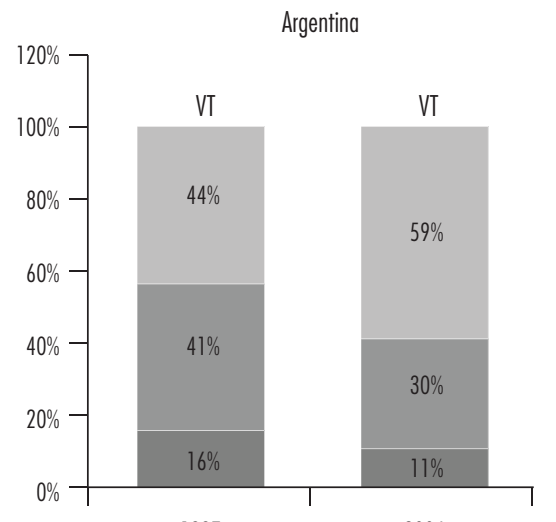

1997

2004

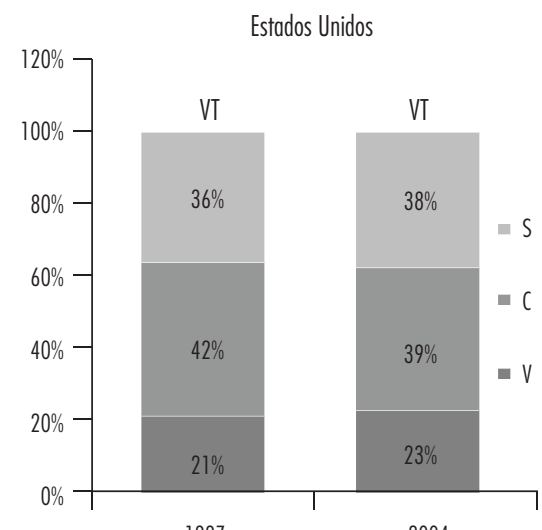

1997
2004

Fuente: elaboración propia con base en datos de Indec y BEA.

De esa manera, comenzamos a percibir un proceso de valorización del capital en la economía argentina que toma una forma particular: una reducida participación asalariada en el valor generado, en comparación con la economía central. ${ }^{21}$

Realizada esta descripción general sobre el valor total y sus componentes para cada país en los años seleccionados, es posible avanzar en la presentación de los indicadores que, como hemos mencionado oportunamente, nos permiten dar cuenta de las sustanciales diferencias que presenta cada momento del ciclo del capital en las economías centrales y en las periféricas.

En primer lugar, refiriéndonos a la primera fase de circulación $(D-M)$ y su articulación con la fase de producción $(M-\ldots-P)$, podemos evaluar la composición orgánica del capital (ecuación 1), la tasa de plusvalor (ecuación 2) y la fuerza productiva del

21 En este punto, Marini (2007) sostiene que en las economías dependientes, como la argentina, el consumo asalariado no representa un componente necesario para la valorización del capital en el espacio de valor nacional. Por este motivo, la caída en la participación de los ingresos percibidos por los trabajadores en el sector productivo pueden expresar la recuperación de la valorización exitosa más que su crisis. Basualdo, por su parte, refiriéndose particularmente a nuestro país señala que "la salida devaluacionista de la convertibilidad fue el epílogo de la más profunda y trágica revancha clasista que llevaron a cabo los sectores dominantes en la Argentina moderna. Su aplicación no sólo desencadenó una redistribución de la riqueza existente sino una debacle en términos de los ingresos, en los cuales los sectores populares estuvieron nuevamente en el epicentro del fenómeno" (Basualdo, 2008:1). 
trabajo (ecuación 3). Estos indicadores son, por tanto, más concretos que los propuestos en el apartado teórico.

La composición orgánica ( $C O C$ ) posee un correlato directo con la definición teórica propuesta. La estimación se realiza con base en el cociente entre capital constante $\left(f j 0^{22}\right.$ y el circulante que surge del Cuadro 3) y la fuerza de trabajo viva (empleo total de la economía). ${ }^{23}$ Como se puede observar en el Cuadro 4, la COC es muy superior en Estados Unidos en los años seleccionados, ${ }^{24}$ siendo 2.4 y 4.7 veces mayor en 1997 y 2004, respectivamente. A su vez, en el país central se incrementa 27\% entre 1997 y 2004, mientras que en Argentina la variación es negativa (se reduce 36\%), explicada esta reducción por la desvalorización del capital constante que se produce mediante la crisis de la convertibilidad del peso (Féliz, 2008).

Cuadro 4. Indicadores de las primeras etapas del ciclo del capital para Argentina y Estados Unidos, 1997-2004

\begin{tabular}{lcrr}
\hline Países & Indicador & 1997 & 2004 \\
\hline \multirow{6}{*}{ Argentina } & COC & 36.45 & 23.33 \\
& TP & 2.74 & 5.51 \\
& FPT1 & 67.87 & 20.97 \\
& FPT2 & 25.64 & 7.69 \\
& TE & 3.35 & 5.66 \\
& TG & $23.3 \%$ & $23.1 \%$ \\
\hline \multirow{6}{*}{ Estados Unidos } & COC & 87.39 & 110.58 \\
& TP & 1.72 & 1.67 \\
& FPT1 & 197.57 & 218.74 \\
& FPT2 & 93.72 & 106.22 \\
& TE & 2.65 & 2.72 \\
& TG & $17.1 \%$ & $14.1 \%$ \\
\hline
\end{tabular}

Fuente: elaboración propia con base en datos de Indec, BEA y BLS.

Esta significativa discrepancia en la proporción de trabajo muerto y fuerza de trabajo aplicadas a la producción de valor posee un impacto diferencial en la fuerza productiva del trabajo (productividad). Para aproximarnos empíricamente a la categoría de FPT,

22 Para calcular el capital fijo se utilizó en cada país el stock de capital total deduciendo la magnitud correspondiente a la construcción residencial. Queda conformado así un stock de capital fijo similar al utilizado por Shaikh y Tonak (1994), Maniatis (2005). Los datos referidos al stock de capital son publicados para Argentina y Estados Unidos por la Dirección Nacional de Cuentas Nacionales (Indec) y el Bureau of Economic Analysis, respectivamente.

Creemos relevante incluir el empleo en todas las esferas (producción, circulación y sector no capitalista), pues consideramos que el trabajo aplicado al mantenimiento del orden social (trabajo socialmente necesario) excede a la mera producción de bienes y servicios. 
utilizamos dos variantes. La primera de ellas (expuesta en el Cuadro 4 como FPT1) se conforma a partir del cociente entre el producto total (que es igual al $V T$ expuesto en el Cuadro 3) y el número de trabajadores empleados en la esfera de la producción $(L p)$. Por su parte, FPT2 se calcula como el cociente entre el producto total y el número de horas trabajadas por los trabajadores de la esfera de la producción $(H p) .{ }^{25}$ Ambas aproximaciones nos permiten verificar que la productividad laboral en Estados Unidos es superior que en Argentina. En 1997-2004, la productividad por trabajador (FPT1) se reduce en Argentina 70\%, mientras que en Estados Unidos se incrementa 12\%. Evaluando la productividad horaria (FPT2), en 1997 un trabajador argentino producía cerca de 26 dólares por hora, mientras que su par estadounidense generaba cuatro veces ese valor por hora trabajada (94 dólares de 2000). Las distancias se acentúan en 2004, puesto que en Argentina el valor por hora cae a 7 dólares, al tiempo que en EU aumenta hasta 106 dólares por hora.

En lo que respecta a la tasa de plusvalor $(T P)$, la misma se obtiene del cociente entre el plusvalor y el capital variable del Cuadro 3. Nuevamente, se aprecian dos comportamientos diferenciales: en Eu la proporción de valor apropiado por el capital en relación con el que reciben los trabajadores en la esfera de la producción, se mantienen relativamente estables. En su lugar, en Argentina la TP se duplica, elevando la diferencia respecto de los niveles de apropiación del valor de Eu de $60 \%$ a $200 \%$, aproximadamente. ${ }^{26}$

Relacionado con este último indicador, en el Cuadro 4 exponemos los valores que toma la tasa de explotación relativa $(T E)$, que no es más que una expresión de la subsunción del trabajo al capital en aquellas esferas en las que no se generan valores de uso respecto de aquellas que sí lo hacen. Más allá de la existencia de actividades que no son consideradas productivas en los términos que hemos propuesto aquí, existe una relación de subordinación de los trabajadores al capital y, por tanto, el tiempo de trabajo necesario (expresado en el salario que reciben dichos trabajadores) será menor al tiempo de trabajo total, lo cual origina una porción de plus-trabajo. Siguiendo a Shaikh y Tonak (1994), estimamos la tasa explotación relativa de cada economía como:

$$
T E=\frac{\frac{H n p}{H p}}{\frac{W n p}{W p}}\left(1+\frac{s}{v}\right)
$$

25 La productividad horaria fue construida, según el país, considerando nuevas fuentes de información compatibles con la que surge de las TIP. En el caso argentino se extrajeron los valores de la Cuenta Generación del Ingreso (Indec), conteniendo los siguientes sectores: Agricultura, Caza, Silvicultura y Ganadería, Pesca; Minas y Canteras; Industria; Construcción; y Transporte, Almacenamiento y Comunicaciones. En cuanto a EU, los sectores incluidos fueron: Goodsproducing; Mining and logging; Construction; Manufacturing; Durable goods; Nondurable goods; Private service-providing, y se extrajeron del Bureau of Labor Statistics (Current Employment Statistics).

Los resultados obtenidos para la tasa de plusvalor de Estados Unidos son levemente inferiores a los estimados por Martínez (2005). Las principales diferencias radican en las consideraciones sobre el trabajo autónomo y su inclusión en el cálculo de las categorías de trabajo productivo e improductivo. Creemos que el tratamiento otorgado por la autora es correcto. Sin embargo, los datos para Argentina en cuanto al trabajo autónomo son precarios y no consistentes con las Cuentas Nacionales. Por ello, quedará pendiente para futuras investigaciones la profundización de estos aspectos. 
Donde $H n p$ representa las horas de trabajo no productivo y Wnp la masa salarial de los trabajadores empleados en actividades no productivas. El Cuadro 4 muestra que la apropiación de los capitalistas que participan en esferas diferentes a la productiva, en relación con la que llevan a cabo los que operan en la esfera de la producción, es más elevada en Argentina que en EU, manteniéndose brechas similares a las que se presentan en la esfera de la producción. ${ }^{27}$

Por último, en el mismo cuadro se ve a la tasa de ganancia $(T G)$ como expresión concreta de la valorización del capital en la economía estadounidense y argentina y, a su vez, como un indicador determinado por el segundo momento del ciclo del capital, pero que se manifiesta en el tercer momento $\left(P-\ldots-M^{\prime}-D\right)$.

En Argentina, la tasa general de ganancia (ecuación 4) se mantiene constante alrededor de $23 \%$, en un nivel muy superior al que se observa en la economía estadounidense, la cual pasa de $17 \%$ en 1997 a 14\% en 2004. Este movimiento implica una caída cercana a $20 \%$ entre los años mencionados, lo cual puede inferirse como resultado del incremento de la $C O C$.

Un aspecto relevante es, como destacan Shaikh y Tonak (1994) y Duménil y Lévy (2002), que una tasa general de ganancia -o tasa de ganancia à la Marx-permite evaluar las posibilidades de valorización del conjunto del capital social con base en la apropiación-distribución del valor producido y las características tecnológicas en un momento histórico determinado. No obstante, para los capitales que operan en cada rama de la producción, es más relevante conocer la porción del plusvalor que apropian efectivamente bajo la forma de utilidad (o ganancia efectiva). Esto significa que puede realizarse un cálculo para detraer todos los componentes del plusvalor que se transfieren en forma de ganancias, intereses y rentas a otros capitales en la rama o bien a otras ramas de producción o al Estado bajo la forma de impuestos. Tomando la aproximación empírica de Maniatis (2005) para la economía griega ${ }^{28}$ la tasa de ganancia efectiva para Argentina pasó de $7.8 \%$ a $14.8 \%$ entre 1997 y 2004, lo cual permite inferir que las ganancias apropiadas efectivamente por el capital que opera en la esfera de la producción se duplicaron, más allá de que la posibilidades de valorización del capital doméstico en su conjunto hayan permanecido invariantes.

Queda por analizar brevemente el tercer momento del ciclo $\left(M^{\prime}-D\right)$. En el Cuadro 5 presentamos los indicadores propuestos en las ecuaciones (5) a (9), que expresan la estructura del producto final $(P F)$. Dichos indicadores nos permiten evaluar las capacidades de acumulación de las diferentes economías y, a su vez, cuál es el espacio de valor predominante para la realización de la riqueza domésticamente generada.

\footnotetext{
Para la esfera de la producción, la tasa de explotación es idéntica a la tasa plusvalor.

28 La expresión para la tasa de ganancia efectiva que utilizamos aquí es: $\pi$ efectivo $=\frac{S-T N a c-W n p}{C+V}$ (véase definiciones en el Cuadro 1).
} 
Un primer elemento por destacar es que en nuestro país las participaciones del consumo de los trabajadores en el $P F$ son notablemente bajas, en especial luego de la caída que se produce entre 1997 y 2004, respecto de las estadounidenses. ${ }^{29}$ Por el contrario, el consumo capitalista en nuestro país - gasto improductivo en términos de la reproducción ampliada del capital-supera $20 \%$ del $P F$, mientras que en Eu los porcentajes no superan $7 \%$.

En segundo lugar, indicamos los valores divergentes de la inversión en capital fijo, que puede considerarse como determinante del éxito de la acumulación de capital y, por tanto, de la valorización futura. En 1997, los niveles de inversión productiva como porcentaje del producto final se distanciaban 18\% a favor del país central. En 2004, I/PF cae fuertemente en Argentina (más de 10 puntos porcentuales). A partir de esta caída la participación de la inversión en el producto final del país central supera en más de $100 \%$ a la existente en esta economía periférica.

Cuadro 5. Indicadores de la estructura del producto final en Argentina y Estados Unidos, 1997 y 2004 en términos porcentuales

\begin{tabular}{lcrc}
\hline Paises & Indicado & 1997 & 2004 \\
\hline \multirow{6}{*}{ Argentina } & CONw/PF & $32.0 \%$ & $16.8 \%$ \\
& CONk/PF & $22.1 \%$ & $21.2 \%$ \\
& I/PF & $37.4 \%$ & $26.2 \%$ \\
& (X-M)/PF & $8.6 \%$ & $35.8 \%$ \\
& G/PF & $0.0 \%$ & $0.0 \%$ \\
\hline \multirow{5}{*}{ Estados Unidos } & CONw/PF & $47.2 \%$ & $55.0 \%$ \\
& CONk/PF & $2.2 \%$ & $6 \%$ \\
& I/PF & $44.1 \%$ & $536 \%$ \\
& (X-M)/PF & $-10.1 \%$ & $-26.6 \%$ \\
& G/PF & $16.5 \%$ & $11.4 \%$ \\
\hline
\end{tabular}

Fuente: elaboración propia con base en datos de Indec y BEA.

En lo que respecta al comercio internacional, en Argentina el capital doméstico se encuentra cada vez más inserto en el ciclo de capital a escala internacional, de modo que el valor producido domésticamente es realizado crecientemente en el exterior (X-IMPO/ $P F$ se incrementa 317\% entre 1997 y 2004). Por el contrario, la profundización de los lazos comerciales que el proceso de apertura pos década del setenta generó, no llevó al capital estadounidense, al menos en su forma comercial, a realizar sus ganancias en

29 Aquí aplicamos la metodología propuesta por Shaihk y Tonak (1994) según la cual el consumo de los trabajadores productivos es igual al capital variable. El supuesto que está detrás de esta metodología es que los trabajadores gastan todo su ingreso. 
forma masiva en el mercado mundial (Duménil y Lévy, 2004). Las participaciones de las exportaciones netas en el producto final son negativas en ambos periodos. Es decir, el espacio nacional ocupa un lugar relevante, no sólo para el capital residente en EU, sino también para los de restantes países que colocan allí sus mercancías. ${ }^{30}$

Finalmente, el Cuadro 5 permite verificar la ausencia de producción de mercancías por parte del Estado en Argentina. Si bien el Estado argentino realiza gastos en una serie de valores de uso, asociados sobre todo a la reproducción y mantenimiento social (salud y educación públicas, principalmente), las empresas de servicios públicos generales, así como también las de recursos estratégicos (petróleo y gas) fueron subastadas en la década de 1990 y no se ha avanzado en su recuperación en el periodo posconvertibilidad. Como señalan Azpiazu y Nochteff, este proceso significó una acelerada tendencia a la concentración y centralización del capital y una "creciente polarización del poder económico en un número acotado de grandes conglomerados de capital nacional y extranjero, tanto en el área industrial como en la economía en su conjunto" (1994:221). Paradójicamente, el Estado estadounidense, propalador de aquellas ideas privatizadoras, si bien ha reducido el gasto público en actividades productivas, hacia 2004 aún mantenía una participación mayor a $10 \%$ del producto final.

\section{CONCLUSIONES}

En el presente trabajo realizamos una reinterpretación de las tablas de insumo-producto de Argentina y Estados Unidos en los años 1997 y 2004, con base en categorías marxianas, considerando las diferencias existentes entre trabajo productivo e improductivo. Por medio de esta relectura de las Cuentas Nacionales se logró una aproximación metodológica que permite mayor grado de coherencia entre las categorías analíticas abstractas propuestas por Marx y su correlato empírico.

Aplicando esta metodología se obtuvieron expresiones concretas para las categorías que permitieron analizar cada uno de los momentos del ciclo del capital, así como también una serie de indicadores significativos desde la perspectiva teórica adoptada, que otorgan evidencia acerca de las divergencias estructurales en la manifestación del ciclo del capital en la economía estadounidense y la argentina.

Como señalan Panitch y Gindin (2005) las importaciones masivas y el déficit comercial de Estados Unidos no reviste un carácter negativo para el capital que allí reside, puesto que estos ingresos son utilizados como un estímulo al crecimiento de otras partes del globo. Para eu, dada su posición imperial y la búsqueda de reproducción de la misma, actúa como "importador en última instancia y macroestabilizador global" (Panitch y Gindin, 2005:65). El argumento seguido por los autores busca destacar que las categorías económicas dependen del contexto, por lo que "hay que introducir las asimetrías del imperio en la interpretación y evaluación de los tipos de cambio, cuentas comerciales, déficit presupuestarios, flujos de capital, deuda internacional. Cualquier evaluación de tales criterios en relación con la cuestión del poderío estadounidense tiene que tener presente que lo que parece un síntoma de crisis en las economías normales" no tiene que serlo necesariamente para el centro imperial" (Panitch y Gindin, 2005:60). 
En primer lugar, la capacidad productiva y el desarrollo tecnológico son muy superiores en Estados Unidos respecto de Argentina. Esto implica, a su vez, que se configura en ésta un modo de ser del capital donde la explotación del trabajo posee un rol predominante para lograr una valorización exitosa (reducida participación del capital variable en el valor total, elevados niveles de tasa de plusvalor y de explotación). Estas implicaciones sobre los primeros momentos del ciclo (circulación inicial y proceso productivo) determinan mayor inflexibilidad en la tasa general de ganancia en Argentina. Sin embargo, los sectores que hemos considerado productivos (Agricultura, Ganadería, Caza, Silvicultura y Pesca; Minería; Industrias Manufactureras; Construcción; Suministros de Electricidad, Gas y Agua; Transporte y Almacenamiento), vieron duplicada su rentabilidad luego de la devaluación del peso. Esto se relaciona directamente con el último momento del ciclo (segunda circulación) en el cual, nuevamente, podemos verificar que el valor producido en Argentina se realiza crecientemente en el mercado mundial, mientras que en Estados Unidos ocurre exactamente lo contrario. Por último, el patrón de producción basado comparativamente más en la explotación del trabajo determina menores niveles de consumo asalariado en relación con el producto final en nuestro país que en la economía central aquí analizada.

\section{BIBLIOGRAFÍA}

Azpiazu, D. y H. Nochteff, El desarrollo ausente, restricciones al desarrollo, neoconservadorismo y elite económica en la Argentina, Buenos Aires, Tesis/Norma, 1994.

Bisang, R., "Apertura, reestructuración industrial y conglomerados económicos", en Revista Desarrollo Económico, núm. especial, vol. 38, Buenos Aires, 1998.

Basualdo E., "La distribución del ingreso y sus condicionantes estructurales", en Derechos humanos en Argentina. Informe 2008, Buenos Aires, Centro de Estudios Legales y Sociales (CELs)/Siglo Xxi Editores, 2008.

Bidet, J., Exploring Marx's Capital. Philosophical, Economic and Political Dimensions, Historical Materialism Book Series, núm. 14, Londres, 2007.

Cámara Izquierdo, S., "A Value Oriented Distinction Between Productive and Unproductive Labour", en Capital \& Class, núm. 90, otoño, 2006, pp. 37-63.

Carcanholo, M., "Dependência e superexploraçáo da força de trabalho no desenvolvimento periférico", en E. Sader y T. Dos Santos (coordinadores), A América Latina e os Desafios da Globalizaçao, San Pablo, Brasil, Editorial воттемpo, 2009.

Cockshott, P., A. Cotrell, y G. Michaelson, "Testing Marx: Some New Results From U.K. Data”, en Capital \& Class, vol. 55 (Spring), 1995, pp. 103-128.

Duménil G. y D. Lévy, Capital Resurgent. Roots of the Neoliberal Revolution, Londres, Harvard Unversity Press, 2004.

- "The Profit Rate: Where and How Much did it Fall? Did it recover? (USA 19482000)", en Review of Radical Political Economics, Vol. 34, num. 4, 2002, pp. 437-461. 
Dussel, E., La producción teórica de Marx. Un comentario a los Grundrisse, México, Siglo XxI Editores, 2004.

Féliz, M., Un estudio sobre la crisis en un país periférico. La economía argentina del crecimiento a la crisis, 1991-2002, tesis doctoral sin publicar, 2008.

Féliz, M., E. López y S. Álvarez Hayes, "Valorización del capital y explotación laboral en una economía periférica. Particularidades del caso argentino en el periodo 19952007”, mimeo, Buenos Aires, 2010.

Frenkel, R. y M. Rapetti, "Política cambiaria y monetaria después del colapso de la convertibilidad”, en Ensayos Económicos, núm. 46, Buenos Aires, Banco Central de la República Argentina, 2007.

Godelier, M., Racionalidad e irracionalidad en economía, México, Siglo xxi editores, 1970.

Heymann, D., "Políticas de reforma y comportamiento macroeconómico: la Argentina en los noventa", en Serie de Reformas Económicas, núm. 61, Santiago, Cepal, 2000.

Indec, “Matriz Insumo Producto, Argentina 1997”, en Instituto Nacional de Estadística y Censos, Ministerio de Economía, disponible en http://www.indec.gov.ar/, 2001.

Lebowitz Michael, A., Más allá de El Capital. La economía política de la clase obrera en Marx, Madrid, Akal, 2005.

Lebowitz, M., "Marx's falling rate of profit: a dialectical view", en The Canadian Journal of Economics, vol. 9, núm 2, mayo, 1976, pp. 232-254.

Malizia, E. y E.D. Bond, "Empirical Test of RAs Method of Interindustry Coefficient Adjustment”, en Journal of Regional Science, vol. 14, núm. 3, 1974, pp. 355-365.

Maniatis, T., "Marxian Macroeconomic Categories in the Greek Economy", en Review of Radical Political Economics, vol. 37, núm. 4, 2005, pp. 494-516,.

Marini, R.M., "Dialéctica de la dependencia", en América Latina dependencia y globalización, Buenos Aires, Clacso-Prometeo Libros, 2007.

__ "El ciclo del capital en la economía dependiente", en U. Oswald (coordinador), Mercado y Dependencia, México, Ed. Nueva Imagen, 1979, pp. 37-55.

Martínez G., "Plusvalor, ingreso de los trabajadores autónomos y diferencias nacionales de tasas de plusvalor", en Problemas del Desarrollo, vol. 35, núm. 142, México, IIECUNAM, julio-septiembre de 2005, pp. 11-35.

Marx, K., Elementos fundamentales para la crítica de la economía politica (Grundrisse), México, Siglo xxi Editores, 2007a.

—_, El Capital, tomo II, vol. 1, México, Siglo xxi Editores, $2007 \mathrm{~b}$.

—_, El Capital, tomo III, vol. 7, México, Siglo xxi Editores, 2006.

— El Capital, tomo I, vol. 1, México, Siglo xxi Editores, 2005.

—, El Capital, tomo I, vol. 2, México, Siglo xxi Editores, 2003.

—, Teorías sobre la plusvalía, Buenos Aires, Editorial Cartago, 1974.

Mecon, Instrumentos para el Análisis Socioeconómico del Plan Estratégico de Energía, Buenos Aires, Ministerio de Economía y Producción, 2007.

Mészáros, I., Beyond Capital: Toward a Theory of Transition, Nueva York, Monthly Review Press, 1995. 
Moseley, F., "The Rate of Profit and the Future of Capitalism", Review of Radical Political Economics, vol. 29, núm. 4, Fall, 1997, pp. 23-41.

—- "The Rate of Surplus Value in the Postwar u.s. Economy: A Critique of Weisskopf's Estimates", en Cambridge Journal of Economics, vol. 9, núm. 1, marzo, 1985, pp. 57-79.

Panitch L. y Gindin S., "Superintending Global Capital”, en New Left Review, vol. 35 , (September-October), 2005, pp. 101-123.

Pedreño, A., "Deducción de las tablas input-output: consideraciones críticas a través de la contrastación survey-nonsurvey”, en Investigaciones Económicas, vol. x, núm. 3, 1986, pp. 579-599.

Saad-Filho, A., "A Note on Marx's Análisis of the Composition of Capital", en Capital \& Class, vol. 50, Conference of Socialist Economists, Londres, 1993, pp. 127-146.

Savran, S. y A. Tonak, "Productive and Unproductive Labor: an Attemp at Clarification and Classification", en Capital \& Class, núm. 68, verano, 1999, pp. 113-152.

Schorr, M., "Cambios en la estructura y el funcionamiento de la industria entre 1976 y 2004", tesis doctoral, disponible en http://www.flacsoandes.org/, 2006.

Shaikh, A., Valor, Acumulación y Crisis, Buenos Aires, Razón y Revolución Ediciones, 2006.

Shaikh, A. y E. Tonak, Measuring the Wealth of Nations. The Political Economy of National Accounts, Cambridge University Press, Cambridge, 1994.

Venida, V., "Marxian Categories Empirically Estimated: the Philippines, 1961-1994", en Review of Radical Political Economics, vol. 39, núm. 1, invierno, 2007, pp. 58-79.

Wolf, E., "The Recent Race of Profits the United Status", en Review of Radical Political Economics, vol. 33, núm. 3, verano, 2001, pp. 315-324. 